\title{
New Pharmacological Approaches to Methamphetamine
}

\section{Dependence}

Nadir A Aliyev ${ }^{1 *}$ and Zafar N Aliyev ${ }^{2}$

${ }^{1}$ Department of Psychiatry and Addiction, Azerbaijan State Advanced Training Institute for Doctors named by A Aliyev, Baku City, U Chagibekov Street.

${ }^{2}$ Azerbaijan Medical University, Department of Psychiatry, Azerbaijan

Corresponding Author: Maharshi Dayanand, Dept. of Psychology, Rajiv Gandhi University (A Central University), Doimukh, Itanagar, Arunachal Pradesh, India.

Received date: November 11, 2021; Accepted date: December 20, 2021; Published date: January 04, 2022

Citation: Nadir A Aliyev, Zafar N Aliyev (2022). New Pharmacological Approaches to Methamphetamine Dependence. Addiction Research and Adolescent Behaviour. 5(1); DOI:10.31579/2688-7517/030

Copyright: (C) 2022 Nadir A Aliyev, This is an open access article distributed under the Creative Commons Attribution License, which permits unrestricted use, distribution, and reproduction in any medium, provided the original work is properly cited.

\begin{tabular}{l} 
Abstract \\
Objectives: This study was carried out with the objectives of investigating the relationship between Family \\
relationship and loneliness in adolescents. Accepted children will score less on loneliness. Neglected children will \\
score high on loneliness. Concentrated children score less on loneliness as compare to accepted children. \\
Method: Sample consisted of 150 adolescent selected by purposive sampling technique. The scales employed for data \\
collection were Family Relationship Inventory by Sherry and Sinha and UCLA loneliness (III) Scale by Russell. \\
Hypothesized that accepted children will score less on loneliness as compare to concentrated and neglected. \\
Results: 150 subjects were taken \& after scoring those high on accepted, concentrated and neglected were selected to \\
form three groups. \\
Conclusion: Findings indicate that the fundamental cause of loneliness is disconnection. Family support and close \\
relationships with their adult children play a central role in adjusting to a new life and in preventing and/or lessening \\
Keywords: methamphetamine addiction; anafrani; carbamazepine; therapy \\
\hline
\end{tabular}

\section{Introduction}

According to [1] WORLD DRUG REPORT 2021, methamphetamine continues to dominate the global production of ATS amphetamine-type stimulants (ATS). During the period 2015-2019, around 24,000 clandestine laboratories used to manufacture ATS1 (45 countries) were discovered or dismantled worldwide. More than 95 percent of them produced methamphetamine. 2019 saw a record number of ATS seized and increased by 64 percent over the previous year, the highest annual growth rate since 2001. The increase in the number of ATS seized over the past decade is mainly attributable to the nearly tenfold amount of methamphetamine seized over the period 2009-2019. Between 2015 and 2019 , methamphetamine accounted for 72 per cent of the total ATS seized worldwide.

The abuse of methamphetamine, a highly addictive and potent stimulant, remains an extremely serious problem in the United States. In some parts of the country, it is even more dangerous than opioids, and it is this drug that most of all contributes to violent crime. [2] According to the 2017 National Survey on Drug Use and Health (NSDUH), more than 14.7 million people (5.4 percent of the population) have tried methamphetamine at least once. NSDUH also reports that nearly 1.6 million people used methamphetamine in the year preceding the survey, 1 and remains one of the most frequently abused stimulants in the world [3].

As a result, methamphetamine abuse causes problems in all walks of life - psychological, medical, social, professional and family. The consequence of methamphetamine use contributes to a number of mental and behavioral disorders as well as somatic disorders such as, aggression, mental and behavioral, damage to the cardiovascular and other body systems. systems, malnutrition and serious dental problems.

As you know, in addition to the devastating effects on human health, methamphetamine abuse threatens entire communities, contributes to new waves of crime, unemployment, neglect and other anti-social activities. A 2009 RAND Corporation report noted that methamphetamine abuse cost the United States approximately \$23.4 billion in 2005 [4].

Methamphetamine is a highly addictive stimulant that affects the central nervous system. It is a white crystalline powder, odorless with a bitter taste, which dissolves easily in water or alcohol. In Azerbaijan, in the 
jargon of drug addicts, it is called glass or stamps. In Azerbaijan, this drug comes from Iran. Only $10 \%$ of this drug is detained by the relevant authorities, the rest of it is transported to Europe. Only $10 \%$ of this drug is detained by the relevant authorities, the rest of it is transported to Europe. As a precursor in Iran, it is made from citric acid or lemon salt, together with asetyl anhydride

Methamphetamine has been classified as a Schedule II stimulant by the US Drug Enforcement Administration, making it legally available only on a one-off prescription basis. Medically, it may be indicated for the treatment of attention deficit hyperactivity disorder (ADHD) and as a short-term component of weight loss treatment, but its use is limited and rarely prescribed; in addition, the prescribed doses are much lower than those usually used incorrectly [5].

\section{Materials and Methods All patients was examined}

This was a double-blind trial for patients diagnosed with DSM-5 for of alcohol dependence. When examining patients, ethical standards were observed in accordance with both international and local legislation. The patients gave their informed, written consent to participate. In accordance with the Helsinki Declaration of the World Medical Association "Recommendations for doctors engaged in biomedical research involving people", adopted by the 18th World Medical Assembly (Finland, 1964, revised in Japan in 1975, Italy-1983, Hong Kong-1989, the South African Republic-1996, Edinburgh-2000); The Constitution of the Republic of Azerbaijan, the Law "On Psychiatric Assistance" (adopted on 12.06.2001, with amendments and additions -11.11.2011, Decisions of the Cabinet of Ministers of the Republic of Azerbaijan No. 83, dated April 30, 2010 "On Approval of the Rules for Conducting Scientific, Preclinical and Clinical studies of medicines" are established. The conditions of the conducted researches corresponded to the generally accepted norms of morality, the requirements of ethical and legal norms, as well as the rights, interests and personal dignity of the participants of the studies were observed.

Conducted research is adequate to the topic of research work.

a) There is no risk for the subject of research.

b) Participants in the study were informed about the goals, methods, expected benefits of the study and associated with risk and inconvenience in the study.

c) The subject's informed consent about participation in the research was received.

The decision of the Ethical Committee at the Azerbaijan Psychiatric Association on the article of NA Aliev, ZN Aliev "New pharmacological approaches to methamphetamine dependence" submitted for publication in psychiatric journals: in connection with compliance with its legislative requirements and regulatory documents is to approve the article by NA Aliyev, Z.N. Aliev "New pharmacological approaches to methamphetamine dependence". The method of randomization core out different methods, we were given by the lottery. This was a double-blind study in patients diagnosed with methamphetamine dependence according to the DSM-5. A total of 100 patients who met the DSM-5 criteria for methamphetamine dependence were examined. All male patients from 18 to 60 years old. The patients were divided into two groups of 50 people: the first group received clomipramine (anafranil) 300 $\mathrm{mg} /$ day (100 mg 3 times a day) and carbamazepine $600 \mathrm{mg} /$ day (200 mg 3 times a day) orally. The second group received an indifferent drug (placebo). Therapy 12 months at the Mental Health Center of the Ministry of Health of the Republic of Azerbaijan. The study was conducted from January 01, 2020 to January 01, 2021, using a double-blind, placebocontrolled method. All patients with other, mental, neurological and somatic diseases were excluded from the study.
For the diagnosis, a clinical interview was used, for DSM-5 Axis I Disorder, Patient Edition, was used to diagnose methamphetamine dependence [6]. All male patients from 18 to 60 years old. The patients were divided into two groups of 50 people: the first group received clomipramine (anafranil) $300 \mathrm{mg} /$ day (100 mg 3 times a day) and carbamazepine $600 \mathrm{mg} /$ day (200 mg 3 times a day) orally. The second group received an indifferent drug (placebo).

The clinical and pharmacological characteristics of anafranil and carbamazepine are sufficiently reflected in the literature on psychopharmacology $[6,7,8]$. Here we will give very brief information about these drugs.

Clomipramine (Anafranil). Nomenclature based on neurology: Serotonin reuptake inhibitor (SRI). Tricyclic antidepressant (TCA). The parent drug is a potent serotonin reuptake inhibitor. The active metabolite is a potent norepinephrine / norepinephrine reuptake inhibitor.

Commonly prescribed to treat: obsessive-compulsive disorder ((in bold, FDA approved)); depression; severe depression that does not respond to treatment; cataplexy syndrome; anxiety; insomnia; neuropathic pain / chronic pain. Mechanism of action:

- Increases the level of neurotransmitters serotonin and norepinephrine / norepinephrine.

- Blocks the serotonin reuptake pump (serotonin transporter), presumably increasing serotonergic neurotransmission.

- Blocks the norepinephrine reuptake pump (norepinephrine transporter), presumably increasing noradrenergic neurotransmission.

- Presumably reduces the sensitivity of both serotonin 1A receptors and beta-adrenergic receptors.

- Because dopamine is inactivated by reuptake of norepinephrine in the frontal cortex, which is largely lacking in dopamine transporters, clomipramine may increase the neurotransmission of dopamine in this part of the brain.

- Carbamazepine (Tegretol, Carbatrol and Equetro). Neurologybased nomenclature: glutamate, voltage-gated sodium and calcium channel blocker (Glu-CB)

- Anticonvulsant, anti-inflammatory agent for chronic pain, antagonist of potential-sensitive sodium channels

- Usually prescribed for

- $\quad$ (in bold, FDA approved)

- Partial seizures with complex symptoms.

- Generalized tonic-clonic seizures (grand mal)

- $\quad$ Mixed seizure patterns

- Pain associated with true trigeminal neuralgia.

- $\quad$ Acute mania / mixed mania (Equetro)

- Neuralgia of the pharynx.

- Bipolar depression.

- Bipolar service

- $\quad$ Psychosis, schizophrenia (in addition)

Acts as a use-dependent blocker of voltage-sensitive sodium channels. Interacts with the open channel conformation of voltage sensitive sodium channels. Interacts with a specific region of the alpha pore-forming subunit of voltage-sensitive sodium channels

Response analysis refers to the last observation carried over for all subjects who had valuable efficacy at baseline and on treatment. Responder analysis was performed using chi-square (x2) and analysis of variance (ANOVA) according to Glantz [10].

\section{Results}


Characteristics of the patients randomly assigned to the two treatments are shown in table 1

\begin{tabular}{|l|l|l|}
\hline Characteristic & $\begin{array}{l}\text { Anafranil and } \\
\text { Carbamazepine n =50 }\end{array}$ & Placebo n = 50 \\
\hline & Mean SD & Mean SD \\
\hline Age (years) & $35.5 \pm 5.5$ & $36.7 \pm 6.0$ \\
\hline $\begin{array}{l}\text { Duration of illness in } \\
\text { month }\end{array}$ & $5,0 \pm 0,5$ & $5,8 \pm 0,6$ \\
\hline $\begin{array}{l}\text { Education: } \\
\text { - primary school }\end{array}$ & $28(56 \%)$ & $30(60 \%)$ \\
- secondary school & $22(44 \%)$ & $20(40 \%)$ \\
\hline $\begin{array}{l}\text { Marital status: } \\
\text { - never married }\end{array}$ & $22(44 \%)$ & $20(40 \%)$ \\
- married & $28(56 \%)$ & $10(25)$ \\
\hline - divorced or separated & & $22(44 \%)$ \\
Employment status & $30(60 \%)$ & $28(56)$ \\
- unemployed & $20(40 \%)$ & \\
\hline
\end{tabular}

Note: differences between groups are not significant

Table 1. Sociodemographic characteristics of patients

Statistical differences between the two groups are no significantly. The results of treatment are shown in Table 2 . The responder was conducted by $\mathrm{X}^{2}$ demonstrated superior for than for placebo (Table 2). Anafranil and Carbamazepine was generally well tolerated by the patients in the study. Anafranil and Carbamazepine group in 10 had short-term breakdowns associated with exposure to microsocial causes. Among patients receiving placebo, only 5 patients experienced remission, all the rest had cases of relapse. There were not unexpected or serious adverse events.

\section{Results}

\begin{tabular}{|l|l|l|l|}
\hline \multirow{2}{*}{ Treatment Groups } & \multicolumn{1}{|c|}{ Observed number } & \multicolumn{1}{|c|}{ Expected number } & \multicolumn{1}{|c|}{ chi-square $\left(\mathbf{x}^{\mathbf{2}}\right)$} \\
\cline { 2 - 4 } & Yes improvement* & Not improvement* & Total \\
\hline Placebo & $5(15.40)$ & $45(12.56)$ & 50 \\
\hline Anafranil and Carbamazepine & $40(13.50)$ & $10(8,0.43)$ & 50 \\
\hline Total & 50 & 50 & 100 \\
\hline
\end{tabular}

Note: expected numbers indication in the brackets $\%^{2}=20.6,2$, df (degree of freedom $=1, p<0.001$.

Table 2: The results of the square analysis.

\section{Discussion}

To date, the most effective treatments for methamphetamine addiction are behavioral therapies, such as cognitive-behavioral interventions and contingency interventions. For example, the matrix model - a 16-week comprehensive approach to behavioral treatment combining behavioral therapy, family education, one-to-one counseling, 12-step support, drug testing, and encouragement for non-drug activities - has been shown to be effective in reducing methamphetamine abuse. [11, 12].

Contingency management activities that provide material incentives in exchange for participating in treatment and maintaining abstinence have also been shown to be effective. Motivational Incentives to Improve Drug Abuse Recovery (MIEDAR), an incentive-based method of encouraging abstinence from cocaine and methamphetamine, has been shown to be effective among methamphetamine abusers through the NIDA National Drug Abuse Clinical Trials Network [13].

In drug development, researchers typically study the effects of potential drugs with neurobiological effects that may counteract the known physiological effects of chronic methamphetamine use. They may also test medications that have proven to be effective in treating other addictions or other mental disorders. The following goals and strategies have shown promising results in animal or human studies associated with methamphetamine use disorder [14, 15].

Transcranial Magnetic Stimulation: TMS is a non-invasive method of brain stimulation using magnetic pulses for therapeutic purposes. Researchers are exploring this approach as a treatment for substance use disorders, but this work is at a very early stage [16]. Neurofeedback: Neurofeedback (also called neurotherapy or neurofeedback) is a type of biofeedback that uses real-time imaging of brain activity (most commonly electroencephalography) to teach people how to regulate their own brain function. In one study, neurofeedback to the treatment of methamphetamine use disorder reduced the severity of addiction and improved mental health and overall quality of life [17].

Vaccines and antibodies: Methamphetamine vaccines, which use the body's immune system to prevent the drug from entering the brain, are currently being tested in animals [18].

\section{Conclusion}

Problems of pharmacological treatment to methamphetamine dependence very problematic. This is the first study on the use of anafranil and cabamazepine, randomized, double-blind placebo-controlled study. Of the 50 patients who received anafranil in combination with cabamazepine, 
40 people went into remission, 10 patients experienced short-term breakdowns associated with exposure to microsocial causes. Among patients receiving placebo, only 5 patients went into remission. Thus, patients with methamphetamine dependence gave a very good result.

Limitation of the study: First, our anafranil in combination with cabamazepine treatment of pharmacological approaches to methamphetamine dependence study group and we recommend that these results be replicated in a larger group so that effect sizes can be more precisely estimated. Second, this work is a necessary study of the possibility of generalizability these data to women. Notwithstanding these limitations, this study suggests that, anafranil in combination with cabamazepine are efficacious and well toler 7 ated in the treatment of pharmacological approaches to methamphetamine dependence.

\section{Conflict of Interest Statement}

The authors declare that the research was conducted in the absence of any commercial or financial relationships that could be construed as a potential conflict of interest.

\section{Acknowledgment}

The authors would like to thank staff of the Mental Health Center of the Ministry of Health of the Republic of Azerbaijan.

\section{References}

1. WORLD DRUG REPORT 2021; UNODC United Nation Office on Drug and Crime drug market trends: cocaine amphetamine- type stimulants.

2. U.S. Department of Justice DEA, Diversion Control Division. National Forensic Laboratory Information System (NFLIS) 2015 Annual Report. 2016.

3. Chomchai C, Chomchai S (2015). Глобальные модели употребления метамфетамина. Curr Opin Psychiatry; 28: 269-74.

4. The RAND Corporation. The economic cost of methamphetamine use in the United States, 2005.The RAND Corporation, 2009. Available at: http://www.rand.org/content/dam/rand/pubs/monographs/2009 /RAND_MG829.pdf. Last accessed March 22, 2013] Last accessed October 102021

5. Kish SJ (2008). Pharmacologic mechanisms of crystal meth. Canadian Medical Association Journal;178:1679.

6. Kaplan \& Sadock's (2017). Comprehensive textbook of psychiatry. Volume I/II tenth edition editors. $12754 \mathrm{PP}$. WOLTERS KLUWER.
7. Alan F. Schatzberg \& Charles B(2017). Nemeroff. The American Psychiatric Association Publishing. TEXTBOOK OF PSYCHOPHARMACOLOGY. EDITED BY Alan F. Schatzberg, Charles B. Nemeroff. FIFTHEDITION. . 2879 pp.

8. Stahl Stephen M. Stephen (2020). STAHL' S ESSENTIAL PSYCHOPHARMACOLOGY. Prescriber's Guide. SEVENTH EDITION. Printed in the United Kingdom by TJ Books Ltd, Padstow Cornwall. ISBN 978-1-108-92601-0 Paperback. ISBN 978-1-108-92602-7 Spiral. 2697 pp.

9. Glantz A. Stanton (2012). Primer of Biostatistics, Seventh Edition., $320 \quad$ pages. ISBN 10: 0071781501 ISBN 13: 9780071781503.

10. Rawson, R.A. Marinelli-Casey, P. Anglin, M.D Dickow, A. Frazier, Y. Gallagher C. J (2003). A multi-site comparison of psychosocial approaches for the treatment of methamphetamine dependence. Addiction 99:708-717.

11. Huber, A. Ling, W, Shoptaw, S Gulati, V Brethen, and Rawson, R. Integrating treatments for methamphetamine abuse: A psychosocial perspective. J Addict Dis 16(4):41-50.

12. Petry, N.M, Peirce, J.M, Stitzer, M.L, Blaine, J Roll, J.M, Cohen, A (2005) .Effect of prize-based incentives on outcomes in stimulant abusers in outpatient psychosocial treatment programs: A National Drug Abuse Treatment Clinical Trials Network study. Arch Gen Psychiatry 62(10):1148-1156.

13. Salo, R.; Buonocore, M.H Leamon, M ,Natsuaki, T, Waters, C Moore, C.D.;Galloway, G.P andNordahl, T.E (2011). Extended findings of brain metabolite normalization in MA-dependent subjects across sustained abstinence: A proton MRS study. Drug and Alcohol Dependence 113(2-3):113- 138.

14. Wang G-J; Volkow, N, Chang, L. Miller, E.,Sedler, M, Hitzemann, R.,Zhu, W, Logan, J,Ma, Y, and Fowler, J.S (2004). Partial recovery of brain metabolism in methamphetamine abusers after protracted abstinence. Am J Psychiatry 161(2):242-248

15. Makani R, Pradhan B, Shah U, Parikh T(2017). Role of Repetitive Transcranial Magnetic Stimulation (rTMS) in Treatment of Addiction and Related Disorders: A Systematic Review. Curr Drug AbuseRev;10:31-43.

16. Rostami R, Dehghani-Arani F (2015) . Neurofeedback Training as a New Method in Treatment of CrystalMethamphetamine Dependent Patients: A Preliminary Study. Appl Psychophysiol Biofeedback.40:151-61.

17. Collins KC, Schlosburg JE, Bremer PT, Janda KD (2016). Methamphetamine Vaccines: Improvement through Hapten Design. J Med Chem; 59:3878-85. 
(C) (1)

This work is licensed under Creative

Commons Attribution 4.0 License

To Submit Your Article Click Here: Submit Manuscript

DOI: $10.31579 / 2688-7517 / 030$
Ready to submit your research? Choose Auctores and benefit from:

* fast, convenient online submission

* rigorous peer review by experienced research in your field

* rapid publication on acceptance

* authors retain copyrights

* unique DOI for all articles

* immediate, unrestricted online access

At Auctores, research is always in progress.

Learn more https://auctoresonline.org/journals/addiction-research-andadolescent-behaviour 